\title{
Ming-Chang Tsai: A Pioneer in Comparative Quality of Life Research
}

\section{Ming-Chang Tsai ${ }^{1}$}

Published online: 26 August 2021

(C) The International Society for Quality-of-Life Studies (ISQOLS) and Springer Nature B.V. 2021

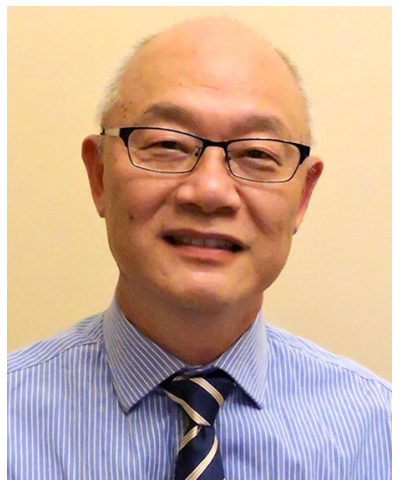

My research interest in well-being study appeared early but became firm over my career. In the late 1970s, social scientists had a lively debate about how Taiwan could become a modernized society, since the societal income level had increased substantially, owing to fast economic growth then. Modernization was a dominant paradigm of social progress imported from abroad. Material, rather than subjective, well-being was the focus back then. In 1982, I studied in the master's program of sociology at National Taiwan University, and became familiar with some left-wing theories debating against modernization theory. What was fashionable at that time in the department was dependency theory, which originated from Latin American scholarship. It contended that huge inequality in life conditions had long existed between countries and classes, and that social and economic development as was desired could not be possibly realized without a socialist revolution to transform the class structure, abolish the corrupt state, and get rid of foreign exploitation. The leftist ideas were inspiring enough. But I had my doubts, as Taiwan seemed to be successful with regards to growth and distribution by way of manufacturing industrial

Ming-Chang Tsai

mtsai304@gate.sinica.edu.tw

1 Research Center for Humanities and Social Sciences, Academia Sinica, Taipei, Taiwan 
products for the global market. Meanwhile, in the late 1980s democratization had appeared to set in when the Kuomintang authoritarian regime that ruled Taiwan for nearly 50 years had lost its legitimacy, and party competition and fair elections became the new rules of the game for political power.

In 1989 I went to State University of New York at Stony Brook to pursue a doctoral degree with a scholarship from the Taiwanese government. I studied with Professor Ian Roxborough, a renowned scholar of Latin America and development studies. I was advised to work on how state structure had affected economic conditions and social spending using macro-level indicators and econometric techniques. In the family of comparative social study such a research design was quite popular at that time. In 1992 I obtained my PhD degree and returned to Taiwan to resume my teaching job at National Taipei University. I moved to Academia Sinica in 2014 and have worked there since.

I continued to concentrate on how macro-structural conditions can exert huge impacts on poverty, life expectancy, and human development in broad terms (Tsai, 2006, 2007, 2009) during my early career. I developed a habit of looking into specific experiences of social conditions and life conditions of the people in selected countries, even though my cross-national studies relied on estimation results from modeling societal indicators for evidence. I believe that this practice adds necessary sociological flesh to the otherwise lean bone of econometric models. I have always enjoyed citing certain countries in empirical papers. I feel like telling a story of how regression models really match what is observed in local social contexts. A recent practice is my invention of a mother's well-being index across the world (Tsai \& Tai, 2018), in which Brazil, the United States and China are highlighted for their distinct policy environments such that their ranking positons relative to other countries can make better sense (see also Tsai, 2021).

My sociological training alerted my attention to different contexts and pathways to well-being when investigating societies across cultures and regions. When I started to regularly participate in the International Society of Quality-of-Life Studies in the early 2000s (the first one was in Frankfurt in 2003), I learned many colleagues were working on subjective well-being by using survey data. I might have started a plan to do research in this direction, but I was still preoccupied with my cross-country studies. In 2008 I happened to obtain a highly interesting and affordable dataset (the Core Welfare Indicators Questionnaire 2003) purchased from the Ghana Statistical Service. This dataset contains numerous variables about household structure, marriage relationships, community relationships and well-being. It is also a large sample with more than 33,000 participants. I decided to work on a collaborative project with friends in the sociology department in the University of Ghana. We used exchange theory as a basic theoretical framework to interpret how secure with food provisions and happy about life Ghanaians felt. Reciprocation turned out to be a strong factor in the explanation, as was expected (Tsai \& Dzorgbo, 2012; Tsai \& Senah, 2014).

I learned two highly important lessons from studying Ghana. In the beginning, some general ideas were adopted from the literature based on studies in western societies. This is of course not enough for scientific papers on a western African coastal society. I read widely and listened to stories about what happens when Ghanaians 
borrow money from others and how they return the favors in specific ways. There seems to be a clear norm guiding reciprocal behaviors. It is both meaningful and important for Ghanaians to have a reputation of being generous in giving. A person with a good past record in giving will receive support from others when needs occur in the future. Exchange behaviors are widely practiced in other societies, but among Ghanaians there is a specific cultural logic in it, which makes it work in a popular way. Give and take between people is not practiced out of rational calculation for personal immediate satisfaction. This is the first lesson I learned.

The second lesson is more relevant to empirical modeling. Regression techniques have been regularly applied for predicting levels of well-being indicators, both objective and subjective. In a comparative setting, either one particular "case society" or more ambitiously a bundle of societies, researchers will duplicate one identical model for all populations, and check whether outcomes for the model behave in a similar manner. As multilevel analysis methods develop, researchers tend to pool all populations across societies and conduct estimation. A catch-all explanation is offered in interpreting the results. Specific differences owing to a country's particular characteristics are controlled by inclusion of societal factors like GDP per capita, etc., or are put away in "random effects". I have no issues with these now-standard practices. My own attitude is that I have to gather information about what the locals would say or think about a predictor I put in a regression equation, particularly when it is culturally distinct. For example, from the first trials of modeling of how Ghanaians felt about whether they were satisfied with food needs and did not feel poor, the regression outcomes showed that those owning big livestock, measured by numbers of "cattle and other large livestock" as provided in the original questionnaire, reported a feeling of security and happiness. I merrily placed three $* * * \quad(p<000)$ next to this significant coefficient of owning livestock and showed it to my Ghanaian co-author. He frowned, and replied: "well, the outcomes are impressive, but its underlying logic is problematic." Here is why: Many Ghanaians own sheep, goats and fowl, and these are likely to be their personal property. However, in the case of cows, these are supposed to be collectively owned family assets. Cows are generally used to organize funerals for important people in the family, to contract marriage, or as sacrifice to the gods and ancestors in times of life crises. Simply put, cows are not equivalent to food, and we provided a cautionary note to readers to that effect. I have been benefiting from my hands-on experience with the fact that variables, even standard ones on demographic background (education, marital status, etc.), can vary in meaning when they appear in different cultural contexts. Nowadays this variance is paid less attention, and social scientists concentrate instead on technical issues like measurement errors, threats to causal inference from endogeneity problems, or choice of instrumental variables.

I have enjoyed learning how people from different groups, societies and cultures access resources, build interpersonal relationships, overcome adversity, and feel fulfilled and happy in different ways (Tsai, 2021). At present, I am mainly working on youths and their life conditions in East Asia, in response to a major argument that youths have been a lost generation in the age of globalization. A comparative perspective can enrich our understanding of how the young cohorts fare at the moment and how their current experiences will have long-term influences in Asia. 


\section{References}

Tsai, M.-C. (2006). Does political democracy enhance human development in developing countries? A cross-national study. American Journal of Economics and Sociology, 65, 233-268.

Tsai, M.-C. (2007). Does globalization affect human well-being? Social Indicators Research, 81, $102-126$.

Tsai, M.-C. (2009). Market openness, transition economies and subjective wellbeing. Journal of Happiness Studies, 10, 523-539.

Tsai, M.-C. (2021). Kin, friend and community social capital: Effects on well-being and prospective life conditions in Japan, South Korea and Taiwan. Social Indicators Research, 154, 489-510.

Tsai, M.-C., \& Dzorgbo, D. S. (2012). Familial reciprocity and subjective well-being in Ghana. Journal of Marriage and Family, 74, 215-228.

Tsai, M.-C., \& Senah, K. (2014). Food security and perceived well-being among household heads in Ghana. Applied Research in Quality of Life, 9, 255-272.

Tsai, M.-C., \& Tai, T.-O. (2018). How are mothers faring across the globe? Constructing a new Mothers' Well-being Index and assessing its validity. Applied Research in Quality of Life, 13, 647-670.

Publisher's Note Springer Nature remains neutral with regard to jurisdictional claims in published maps and institutional affiliations. 